\title{
Economical synthesis strategy, characterization and theoretical study of the organic dye 3-oxo-3H-spiro [isobenzofuran-1,9'-xanthene]-3',6'- diyl dibenzoate
}

\author{
Nadia Arrousse ${ }^{1}$ El Houssine Mabrouk ${ }^{1,2} \cdot$ Khadija Ismaily Alaoui $^{1}$. Fadoua El Hajjaji ${ }^{1} \cdot$ Zakia Rais $^{1}$. \\ Mustapha Taleb ${ }^{1}$
}

Received: 19 February 2020 / Accepted: 15 April 2020 / Published online: 5 May 2020

(c) Springer Nature Switzerland AG 2020

\begin{abstract}
In the present work, the economical synthesis strategy of the compound in high yield was reported through the reaction between fluorescein and benzoyl chloride under different operating conditions. The synthesized compound: 3-oxo-3Hspiro[isobenzofuran-1,9'-xanthene]-3',6'-diyldibenzoate was characterized by IR, ${ }^{1} \mathrm{H}$ NMR, ${ }^{13} \mathrm{C}-\mathrm{NMR}$ and mass spectral. This reaction has been studied also theoretically using Gaussian 09 based on the DFT method at B3LYP/6-311G (d, p). The results revealed that the theoretical study is in good correlation with the experimental one. The analysis of the absorption spectrum shows that the prepared product which has optical properties is a colored pigment.
\end{abstract}

Keywords O-benzoylation • Fluorescein · Benzoyl chloride · DFT/B3LYP method/6-311G base (d, p)

\section{Introduction}

The chemistry of heterocyclic compounds has received much attention owing to its synthetic and effective biological importance [1-9]. They have been incorporated into a variety of therapeutically appealing drug candidates including antiviral, anti-migraine, antifungal, antianxiety compounds. The heterocyclic chemistry occupies a prime place in medicinal and pesticide chemical science due to their capability to exhibit a wide range of bioactivities, such as antimicrobial [10-14], anticancer [15], antiinflammatory [16, 17], antidepressant [18], anticonvulsant [19], antipyretic [20], selective enzyme inhibitory activities [21], etc.

Fluorescence typically occurs in aromatic molecules and heterocycles, called fluorophores or fluorescent dyes. Fluorescent particles always contain a chromophore, the part of a molecule responsible for its color. These endogenous fluorophores are responsible for the autofluorescence of biological structures like mitochondria or lysosomes [22]. Polycyclic aromatic compounds represent a class of fluorescent dyes widely applied as useful synthetic biomolecule labels $[23,24]$. Our team has been investigating the fluorescein for their biological activity for several years. The development of efficient methods for the formation of the $\mathrm{C}-\mathrm{O}$ bond via the acylation of $\mathrm{O}-\mathrm{H}$ bonds is one of the primary subjects in organic synthetic chemistry. Because of these and the continuation of our research, the synthesis of heterocyclic systems of xanthene derivations and biologically active molecules, we hereby report the preparation of new fluorescein derivative and the theoretical study of its reaction.

3-oxo-3H-spiro[isobenzofuran-1,9'-xanthene]-3',6'-diyl (3-dibenzoate) previously synthesized by Hossein Eshghi

$\square$ El Houssine Mabrouk, mabrouk.elhoussine@gmail.com | 'Laboratory of Engineering, organometallic, Molecular and Environment (LIMMOME), Faculty of Sciences, University Sidi Mohamed Ben Abdellah, Fez, Morocco. ${ }^{2}$ Laboratory of Materials Engineering for the Environment and Natural Resources, Department of Chemistry, Faculty of Sciences and Technics, Moulay Ismail University Meknes, BP 509 Boutalamine, Errachidia, Morocco. 
and al. [25] catalytically using $\mathrm{P}_{2} \mathrm{O}_{5} / \mathrm{SiO}_{2}$. This work aims to synthesize the same product with an economical method. Not only that, but the result also obtained experimentally has been confirmed theoretically using Gaussian 09 .

\section{Results and discussion}

Our strategy is based on the $O$-benzoylation reaction of benzoyl chloride $\mathbf{2}$ with fluorescein $\mathbf{1}$ (Scheme 1). As a first step and to optimize the different experimental conditions (choice of solvent, base...), we conducted several test reactions. For all these tests, the reactions were followed by TLC and ${ }^{1} H$ NMR. The Infrared spectroscopic studies show the bands confirming the presence of the groups $\mathrm{C}=\mathrm{O}, \mathrm{C}-\mathrm{O}, \mathrm{C}=\mathrm{C}$, and $=\mathrm{CH}$. Yields are given as pure product after recrystallization from acetone/methanol.

The $O$-benzoylation reaction was carried out in numerous solvents (DCM, acetone, $\mathrm{CH}_{3} \mathrm{CN}$ or toluene) for $4 \mathrm{~h}$ at $0{ }^{\circ} \mathrm{C}$ in addition to $4 \mathrm{~h}$ at room temperature in the presence of various bases $\left(\mathrm{Et}_{3} \mathrm{~N}\right.$, pyridine or $\left.\mathrm{NaOH}\right)$. The new organic dye $\mathbf{3}$ synthesized with satisfactory yields was identified by nuclear magnetic resonance, infrared and mass spectrometry. The results are summarized in Table 1 .
In summary, after several attempts of reactions without base or in a basic medium, like triethylamine $\left(\mathrm{Et}_{3} \mathrm{~N}\right)$, pyridine and sodium hydroxide, the use of $\mathrm{Et}_{3} \mathrm{~N}$ in dry acetone gives the best results. The solvents played a significant role in the substitution of fluorescein. Further studies established absolute acetone also was the best choice among the solvents (DCM, acetone, $\mathrm{CH}_{3} \mathrm{CN}$ and toluene) screened (Table 1). The use only of solvents in the absence of a base in all the reactions does not make it possible to obtain the desired product.

As shown in Scheme 1, the O-benzoylation of benzoyl chloride $\mathbf{2}$ with fluorescein $\mathbf{1}$ leads to the specific product 3-oxo-3H-spiro[isobenzofuran-1,9'-xanthene]-3',6'-diyl dibenzoate 3 with an extraordinarily high yield. This justified reaction is carried out in dry acetone for $4 \mathrm{~h}$ at $0^{\circ} \mathrm{C}$ in addition to $4 \mathrm{~h}$ at room temperature in the active presence of triethylamine. The new xanthene derivative was detected by conventional spectroscopic techniques, like ${ }^{1} \mathrm{H}-\mathrm{NMR},{ }^{13} \mathrm{C}-\mathrm{NMR}$, Infrared and MS.

Our interest is to use economic experimental conditions, that is why we do not have the advantage of varying the temperature especially since we obtained good yields. The reaction is exothermic, the enthalpy value of the $\Delta \mathrm{H}_{\mathrm{r}}$ is negative (see the part of the theoretical study).

This result cannot be explained without a theoretical study because we expect to obtain several products with different yields:

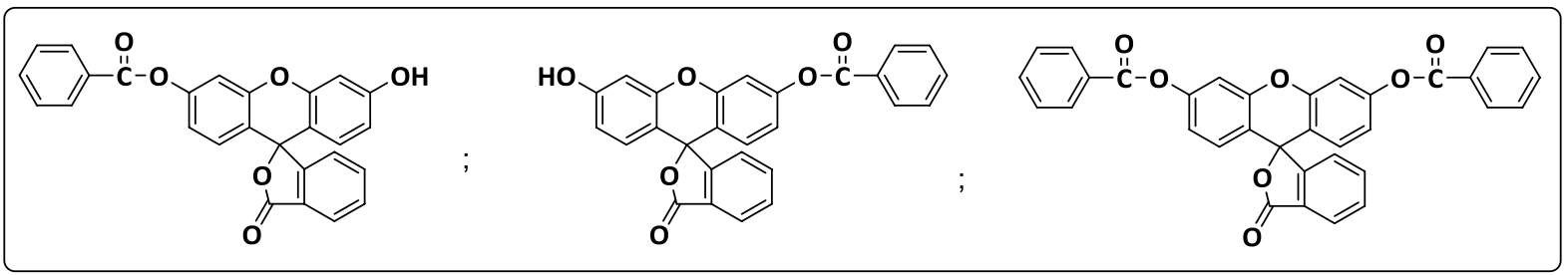

Scheme 1 O-benzoylation reaction of benzoyl chloride 2 with fluorescein 1

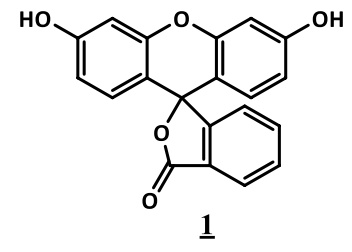

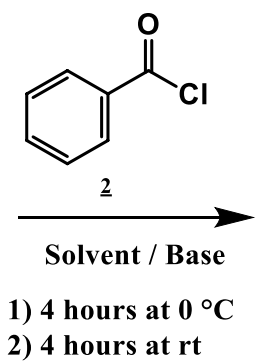

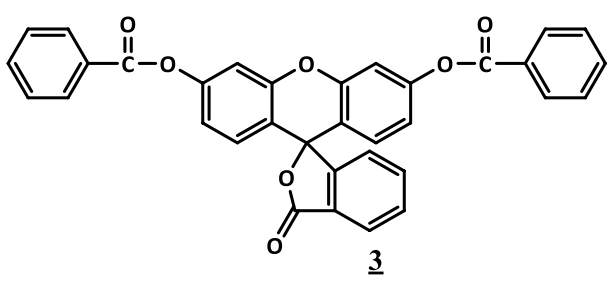

Table 1 Optimization of reaction conditions

\begin{tabular}{|c|c|c|c|c|c|c|c|c|}
\hline Reaction conditions & $-D C M$ & -Toluene & -Acetone & $\mathrm{NaOH}$ Toluene & $\mathrm{NaOH}$ Acetone & Pyridine Acetone & $\mathrm{Et}_{3} \mathrm{NCH}_{3} \mathrm{CN}$ & $\mathrm{Et}_{3} \mathrm{~N}$ Acetone \\
\hline Yield (\%) & 0 & 0 & 0 & 52 & 68 & 74 & 86 & 92 \\
\hline Reaction Time (h) & $8 \mathrm{~h}$ & & & & & & & \\
\hline
\end{tabular}

DCM dichloromethane, $\mathrm{CH}_{3} \mathrm{CN}$ acetonitrile, $\mathrm{Et}_{3} \mathrm{~N}$ triethylamine 
The theoretical study reported in this work clearly shows the spatial symmetry of the fluorescein molecule, which justifies the formation of a single product.

On the other hand and to study the optical properties of the synthesized product towards the light, we carried out its absorption spectrum. The analysis of this spectrum shows:

The maximum absorbance of the synthesis product was naturally taken at a specific wavelength of $400-650 \mathrm{~nm}$ typically using a UV/Visible spectrophotometer (UV6300PC, Double Beam Spectrophotometer). From the absorption spectrum, it appears prominently that the unique product synthesized efficiently is a colored pigment (organic dye). The maximum absorption $(\mathbf{A}=\mathbf{1 . 5}$ ) precisely corresponds to a visible wavelength of $\mathbf{5 3 0} \mathbf{~ n m}$ reasonably relating to a fluorescent coloring between green and yellow (Fig. 1).

\section{Experimental section}

\subsection{General}

Melting points were determined with an Electrothermal melting point apparatus and are uncorrected. NMR spectra $\left({ }^{1} \mathrm{H},{ }^{13} \mathrm{C}\right)$ were recorded on a Bruker AM 300 (operating at $300.13 \mathrm{MHz}$ for ${ }^{1} \mathrm{H}$, at $75.47 \mathrm{MHz}$ for ${ }^{13} \mathrm{C}$ ) spectrometer (Regional University Center of Interface, Fez). NMR data are listed in ppm and are reported relative to tetramethylsilane $\left({ }^{1} \mathrm{H},{ }^{13} \mathrm{C}\right)$; residual solvent peaks being used as an internal standard. All reactions were followed by TLC. TLC

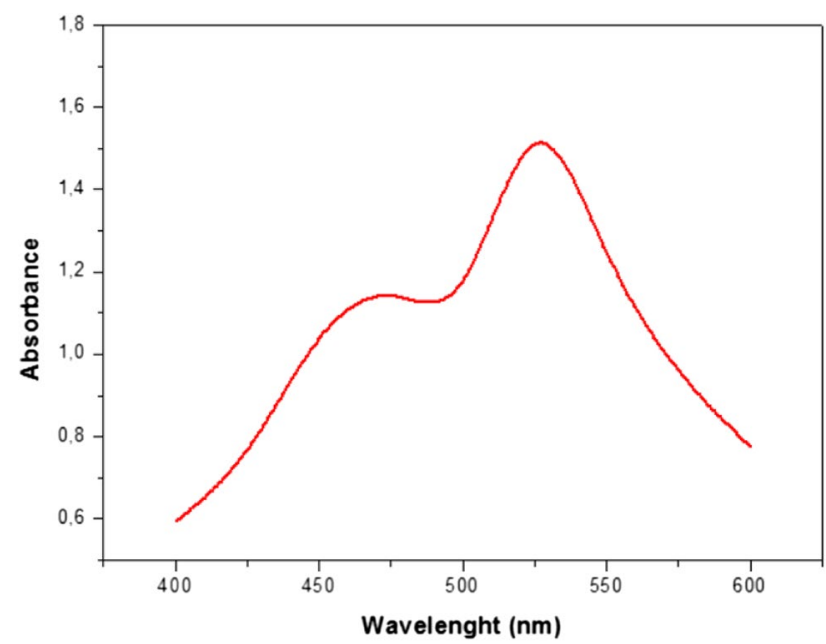

Fig. 1 The absorption spectrum of product 3 analyses were carried out on $0.25 \mathrm{~mm}$ thick precoated silica gel plates (Merck Fertig platen Kieselgel 60F254) and spots were visualized under UV light or by exposure to vaporized iodine. Mass spectra were recorded on a Polaris $\mathrm{Q}$ Ion Trap GC/MSn Mass Spectrometer (Regional University Center of Interface, Fez).

\subsection{The typical procedure for 0 -benzoylation}

To a stirred solution of fluorescein $(0.34 \mathrm{~g}, 1 \mathrm{mmol})$ in $5 \mathrm{ml}$ of the solvent cooled to $0{ }^{\circ} \mathrm{C}, 1.1 \mathrm{mmol}$ of the base was added. After $30 \mathrm{~min}$ of stirring, the $\mathrm{pH}$ of the solution is approximately 14 . Benzoyl chloride $(0.4 \mathrm{~g}, 2 \mathrm{mmol}, 2.0$ equiv) in $3 \mathrm{~mL}$ of a solvent was added dropwise over $2 \mathrm{~h}$ with continuous cooling. The solution was cooled an additional $2 \mathrm{~h}$. TLC monitored the mixture on silica gel (Ether/ Hexane, 80: 20). After $4 \mathrm{~h}$, the conversion of the starting material was complete, and a new product was noticed. The solvent was evaporated under reduced pressure. The residue was quenched with a saturated aqueous solution of ammonium chloride $(20 \mathrm{~mL})$ and extracted with dichloromethane $(20 \mathrm{~mL} \times 3)$. The organic phase was sufficiently dried in sodium sulfate $\left(\mathrm{Na}_{2} \mathrm{SO}_{4}\right)$ and the suitable solvent was removed under reduced pressure. The product was purified by twice the recrystallization from acetone/ methanol. The product was obtained as a transparent solid with an excellent yield.

\subsection{3-oxo-3H-spiro[isobenzofuran-1,9'-xanthene]-3 ',6'-diyl dibenzoate 3}

Yield $=92 \%$; Melting point (ether/hexane): $212{ }^{\circ} C_{i}$; $\mathrm{R}_{\mathrm{f}}=0.85$ (ether). ${ }^{1} \mathbf{H}-\mathbf{N M R}$ (Bruker, $300.13 \mathbf{~ M H z}, \mathbf{C D C l}_{3}$ ): $\delta$ $(\mathrm{ppm})=6.92-7.01\left(\mathrm{~m}, 4 \mathrm{H}, \mathrm{H}_{\text {arom }}\right), 7.26-7.29\left(\mathrm{~m}, 3 \mathrm{H}, \mathrm{H}_{\text {arom }}\right)$, 7.53-7.58 (m, 4H, $\left.\mathrm{H}_{\text {arom }}\right), 7.66-7.77\left(\mathrm{~m}, 4 \mathrm{H}, \mathrm{H}_{\text {arom }}\right), 8.08-8.10$ $\left(\mathrm{m}, 1 \mathrm{H}, \mathrm{H}_{\text {arom }}\right), 8.20-8.26\left(\mathrm{~m}, 4 \mathrm{H}, \mathrm{H}_{\text {arom }}\right)$.

${ }^{13}$ C-NMR (75.47 MHz; $\left.\mathrm{CDCl}_{3}\right): \delta(\mathrm{ppm})=81.75(\mathrm{C}-\underline{\mathrm{C}}-\mathrm{O})$, $110.62(2 \mathrm{C}), 116.61(1 \mathrm{C}), 117.93(2 \mathrm{C}), 124.14(1 \mathrm{C}), 125.26$ (1C), 126.16 (1C), 128.68 (6C), 129.01 (2C), 129.08 (1C), $130.11(1 \mathrm{C}), 130.30(6 \mathrm{C}), 133.92(2 \mathrm{C}), 135.32(1 \mathrm{C}), 151.70$ (1C), $152.41(1 \mathrm{C}), 153.04(1 \mathrm{C})\left(\mathrm{C}_{6} \mathrm{H}_{5}\right.$ aromatic carbons), 164.62 (2CO), 169.18 (CO). MS-El: 540.54 [M], $\mathrm{C}_{34} \mathrm{H}_{20} \mathrm{O}_{7}$.

FT-IR $\tilde{\mathrm{V}}\left(\mathrm{cm}^{-1}\right) 3065 \mathrm{v}(=\mathrm{C}-\mathrm{H}$, aromatic), $1747 \mathrm{v}(\mathrm{C}=\mathrm{O}$, lactone), $1610 \vee(C=C$, arom.), $1240 \vee(C-O), 1060, v(C-C)$. 


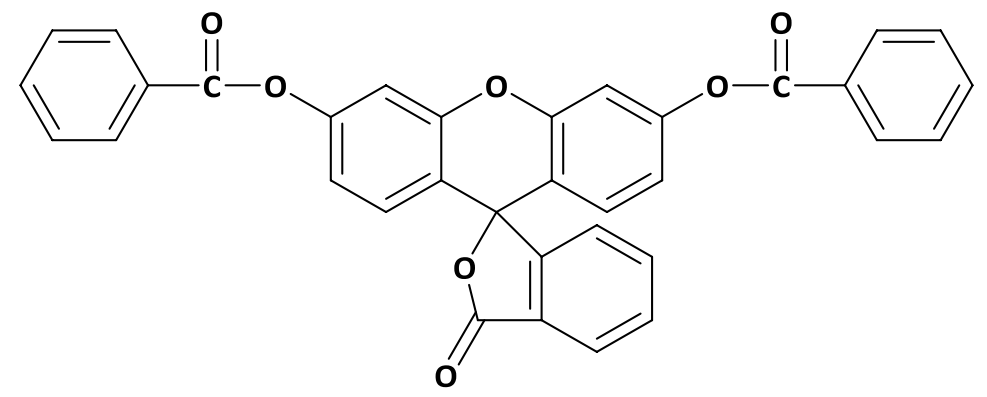

\section{Theoretical study of the synthesis reaction}

\subsection{Calculation methodology}

In this completed work, we typically used:

- The DFT/B3LYP density functional theory method with the $6-311 \mathrm{G}$ base $(d, p)$ for quantum calculations.
- The GaussView 5.0 program for the construction of molecular models and the visualization of geometries.

- The GAUSSIAN 09 program for the optimization of equilibrium geometries.

- Natural Population Analysis (NPA) for calculating local indices of the reactivity.

- The MARVINSKETCH program to determine the distribution of different forms of fluorescein with $\mathrm{pH}$.

Table 2 Interatomic distances of fluorescein (R1) and benzoyl chloride (R2) found after optimization by the methods DFT/6-311G (d, p), $\mathrm{HF} / 6-311 \mathrm{G}(\mathrm{d}, \mathrm{p})$ and MP2/6-311G (d, p)

\begin{tabular}{|c|c|c|c|}
\hline \multirow{2}{*}{$\begin{array}{l}\text { Reagents } \\
\text { Geometry }\end{array}$} & \multicolumn{3}{|c|}{ Interatomic distances } \\
\hline & \multicolumn{3}{|c|}{ Calculation methods } \\
\hline & DFT/6-31G $(d, p)$ & $H F / 6-31(d, p)$ & MP2/6-31G $(d, p)$ \\
\hline & $\mathrm{dC}_{1}-\mathrm{C}_{2}=1.396$ & $\mathrm{dC}_{1}-\mathrm{C}_{2}=1.394$ & $\mathrm{dC}_{1}-\mathrm{C}_{2}=1.389$ \\
\hline & $\mathrm{dC}_{1}-\mathrm{C}_{3}=1.405$ & $\mathrm{dC}_{1}-\mathrm{C}_{3}=1.407$ & $\mathrm{dC}_{1}-\mathrm{C}_{3}=1.408$ \\
\hline & $\mathrm{dC}_{3}-\mathrm{H}_{26}=1.085$ & $\mathrm{dC}_{3}-\mathrm{H}_{26}=1.082$ & $\mathrm{dC}_{3}-\mathrm{H}_{26}=1.084$ \\
\hline & $\mathrm{dC}_{3}=\mathrm{C}_{5}=1.384$ & $\mathrm{dC}_{3}=\mathrm{C}_{5}=1.388$ & $\mathrm{dC}_{3}=\mathrm{C}_{5}=1.389$ \\
\hline & $\mathrm{dC}_{5}-\mathrm{C}_{6}=1.404$ & $\mathrm{dC}_{5}-\mathrm{C}_{6}=1.407$ & $\mathrm{dC}_{5}-\mathrm{C}_{6}=1.409$ \\
\hline & $\mathrm{dC}_{6}-\mathrm{O}_{16}=1.362$ & $\mathrm{dC}_{6}-\mathrm{O}_{16}=1.363$ & $\mathrm{dC}_{6}-\mathrm{O}_{16}=1.365$ \\
\hline & $\mathrm{dO}_{16}-\mathrm{H}_{33}=0.966$ & $\mathrm{dO}_{16}-\mathrm{H}_{33}=0.950$ & $\mathrm{dO}_{16}-\mathrm{H}_{33}=0.972$ \\
\hline & $\mathrm{dC}_{2}-\mathrm{O}_{10}=1.369$ & $\mathrm{dC}_{2}-\mathrm{O}_{10}=1.371$ & $\mathrm{dC}_{2}-\mathrm{O}_{10}=1.372$ \\
\hline & $\mathrm{dC}_{24}=\mathrm{O}_{25}=1.206$ & $\mathrm{dC}_{24}=\mathrm{O}_{25}=1.205$ & $\mathrm{dC}_{24}=\mathrm{O}_{25}=1.207$ \\
\hline & $\mathrm{dC}_{18}-\mathrm{C}_{24}=1.482$ & $\mathrm{dC}_{18}-\mathrm{C}_{24}=1.480$ & $\mathrm{dC}_{18}-\mathrm{C}_{24}=1.482$ \\
\hline & $\mathrm{dC}_{9}-\mathrm{C}_{17}=1.523$ & $\mathrm{dC}_{9}-\mathrm{C}_{17}=1.527$ & $\mathrm{dC}_{9}-\mathrm{C}_{17}=1.528$ \\
\hline & $\mathrm{dC}_{1}-\mathrm{H}_{12}=1.082$ & $\mathrm{dC}_{1}-\mathrm{H}_{12}=1.088$ & $\mathrm{dC}_{1}-\mathrm{H}_{12}=1.086$ \\
\hline & $\mathrm{dC}_{1}-\mathrm{C}_{2}=1.403$ & $\mathrm{dC}_{1}-\mathrm{C}_{2}=1.407$ & $\mathrm{dC}_{1}-\mathrm{C}_{2}=1.408$ \\
\hline & $\mathrm{dC}_{2}=\mathrm{C}_{4}=1.394$ & $\mathrm{dC}_{2}=\mathrm{C}_{4}=1.404$ & $\mathrm{dC}_{2}=\mathrm{C}_{4}=1.403$ \\
\hline & $\mathrm{dC}_{7}-\mathrm{Cl}=1.848$ & $\mathrm{dC}_{7}-\mathrm{Cl}=1.850$ & $\mathrm{dC}_{7}-\mathrm{Cl}=1.853$ \\
\hline & $\mathrm{dC}_{7}=\mathrm{O}=1.457$ & $d C_{7}=O=1.459$ & $\mathrm{dC}_{7}=\mathrm{O}=1.461$ \\
\hline & $\mathrm{dC}_{1}-\mathrm{C}_{7}=1.474$ & $\mathrm{dC}_{1}-\mathrm{C}_{7}=1.470$ & $\mathrm{dC}_{1}-\mathrm{C}_{7}=1.471$ \\
\hline
\end{tabular}




\section{Calculation time evolution of reageants according to calculation method}

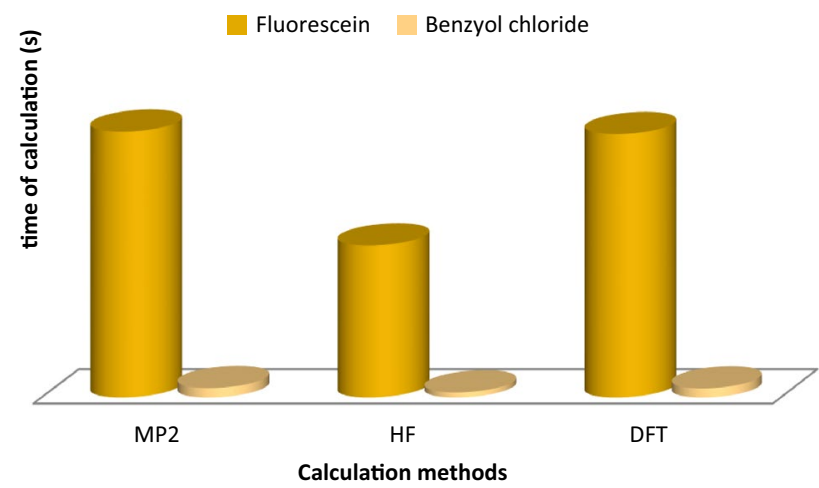

Fig. 2 Evolution of time of optimization of the two reagents in second for the methods: DFT/B3LYP, MP2, HF

\subsection{Results and discussions}

\subsubsection{Justification for choosing the DFT/B3LYP method}

To justify the choice of the DFT/B3LYP computation method used in the rest of this work, it is necessary to make a comparison between the main calculation methods implemented in the Gaussian 09 software.

In addition to the DFT/B3LYP computation with the 6-311G base $(d, p)$, we have chosen two others: semiempirical (MP2/6-311G (d, p)) and Hartree-Fock (HF/6$311 \mathrm{G}(\mathrm{d}, \mathrm{p}))$, the calculations are applied for the reagents of the reaction studied.

4.2.1.1 Comparison of interatomic distances From the results of Table 2 we find that the method DFT/6-311G (d, p) gives interatomic distances closer to the real values.

4.2.1.2 Comparison of calculation time Time represents money. We consistently try performing efficient calculations but in the briefest duration possible, for this reason the time remains among the most important factors in the choice of the method [26, 27].

The optimization time in seconds of each of the two reagents for each method is represented in the form of a diagram (Fig. 2).

From Fig. 2 it can be seen that the method that gives the calculation results in the minimum possible time remains the HF, while the two others: DFT and MP2 give the results with a longer time.

4.2.1.3 Comparison of the total energy given by each method To confirm the most effective method, one must
Table $3 \mathbf{E}_{\text {total }}$ eV fluorescein and benzoyl chloride for DFT, MP2, and HF methods

\begin{tabular}{llll}
\hline Energy $(\mathrm{eV})$ & $\mathrm{MP2}$ & $\mathrm{HF}$ & $\mathrm{DFT}$ \\
\hline R1 & $-31,167.5256$ & $-31,169.7081$ & $-31,171.2957$ \\
R2 & $-21,906.7001$ & $-21,908.4612$ & $-21,910.5026$ \\
\hline
\end{tabular}

Table 4 The density of charge of the atoms of the two reagents

\begin{tabular}{llll}
\hline Fluorescein (R1) & & \multicolumn{2}{l}{ Benzoyl chloride (R2) } \\
\hline $\mathrm{C}_{1 ;} \mathrm{C}_{7}$ & 0.11 & $\mathrm{C}_{1}$ & 0.07 \\
$\mathrm{C}_{2} ; \mathrm{C}_{8}$ & 0.28 & $\mathrm{C}_{2} ; \mathrm{C}_{4}$ & -0.10 \\
$\mathrm{C}_{3} ; \mathrm{C}_{11} ; \mathrm{C}_{13}$ & -0.14 & $\mathrm{C}_{3} ; \mathrm{C}_{5}$ & -0.09 \\
$\mathrm{C}_{4}$ & -0.19 & $\mathrm{C}_{6}$ & -0.06 \\
$\mathrm{C}_{5} ; \mathrm{C}_{19}$ & -0.12 & $\mathrm{C}_{7}$ & 0.25 \\
$\mathrm{C}_{6} ; \mathrm{C}_{12}$ & 0.33 & $\mathrm{O}_{8}$ & -0.37 \\
$\mathrm{C}_{9}$ & 0.06 & $\mathrm{Cl}_{9}$ & -0.10 \\
$\mathrm{O}_{15} ; \mathrm{O}_{16}$ & -0.57 & & \\
$\mathrm{O}_{18}$ & -0.56 & & \\
$\mathrm{O}_{23}$ & -0.50 & & \\
$\mathrm{O}_{25}$ & -0.51 & & \\
\hline
\end{tabular}

also take into account the total energy obtained by each calculation for the two reagents.

Table 3 represents the total eV energy values of fluorescein and benzoyl chloride given by DFT, MP2, and HF.

From the results in Table 3, the lowest total energy for both reagents is given by the DFT computation.

In conclusion, this last makes it possible, after continuous optimization, to obtain interatomic distances that are closer than those of reality; also the lowest total energy values and with reasonable calculation times hence the justification for our preferred choice of the DFT as a calculation method in the present work.

\subsubsection{Optimization of interatomic distances and determination of the density of charges and the angles of the reagents}

The optimized structures allow direct access to all the parameters related to the geometry of the molecules, namely: the densities of charges, the interatomic distances, the angles. All our calculations were performed by the DFT/B3LYP density functional theory method, with the base 6-311G $(d, p)$. The values of these quantities are collated in Tables 4 and 5. The optimized reagent geometries are respectively shown in Figs. 2, 3, 4. 
Table 5 Interatomic distances and angles corresponding to reagents

\begin{tabular}{|c|c|c|}
\hline Reagents & Distance $\AA$ & Angle $^{\circ}$ \\
\hline $\mathrm{R} 1$ & $\begin{array}{l}\mathrm{dC} C_{1}-C_{2}=1.396 \\
\mathrm{dC}_{1}-\mathrm{C}_{3}=1.405 \\
\mathrm{dC}_{3}-\mathrm{H}_{26}=1.085 \\
\mathrm{dC}_{3}=\mathrm{C}_{5}=1.384 \\
\mathrm{dC}_{5}-\mathrm{C}_{6}=1.404 \\
\mathrm{dC}_{6}-\mathrm{O}_{16}=1.362 \\
\mathrm{dO}_{16}-\mathrm{H}_{33}=0.966 \\
\mathrm{dC}_{2}-\mathrm{O}_{10}=1.369 \\
\mathrm{dC}_{24}=\mathrm{O}_{25}=1.206 \\
\mathrm{dC}_{18}-\mathrm{C}_{24}=1.482 \\
\mathrm{dC}_{9}-\mathrm{C}_{17}=1.523\end{array}$ & $\begin{array}{l}\mathrm{A}\left(\mathrm{C}_{1}, \mathrm{C}_{2}, \mathrm{C}_{3}\right)=31.305^{\circ} \\
\mathrm{A}\left(\mathrm{C}_{3}, \mathrm{C}_{4}, \mathrm{C}_{5}\right)=120.038^{\circ} \\
\mathrm{A}\left(\mathrm{O}_{16}, \mathrm{C}_{6}, \mathrm{C}_{5}\right)=117.201^{\circ} \\
\mathrm{A}\left(\mathrm{O}_{23}, \mathrm{C}_{24}, \mathrm{O}_{25}\right)=122.190^{\circ}\end{array}$ \\
\hline $\mathrm{R} 2$ & $\begin{array}{l}\mathrm{dC} C_{1}-\mathrm{H}_{12}=1.093 \\
\mathrm{dC}_{1}-\mathrm{C}_{2}=1.508 \\
\mathrm{dC}_{2}=\mathrm{C}_{4}=1.403 \\
\mathrm{dC}_{3}-\mathrm{H}_{15}=1.086 \\
\mathrm{dC}_{3}=\mathrm{C}_{5}=1.391 \\
\mathrm{dC} C_{5}-\mathrm{C}_{7}=1.395\end{array}$ & $\begin{array}{l}\mathrm{A}\left(\mathrm{C}_{1}, \mathrm{C}_{2}, \mathrm{C}_{3}\right)=119.931^{\circ} \\
\mathrm{A}\left(\mathrm{C}_{1}, \mathrm{C}_{7}, \mathrm{O}_{8}\right)=127.145^{\circ} \\
\mathrm{A}\left(\mathrm{C}_{1}, \mathrm{C}_{7}, \mathrm{Cl}_{9}\right)=115.327^{\circ} \\
\mathrm{A}\left(\mathrm{O}_{8}, \mathrm{C}_{7}, \mathrm{Cl}\right)=117.527^{\circ}\end{array}$ \\
\hline
\end{tabular}

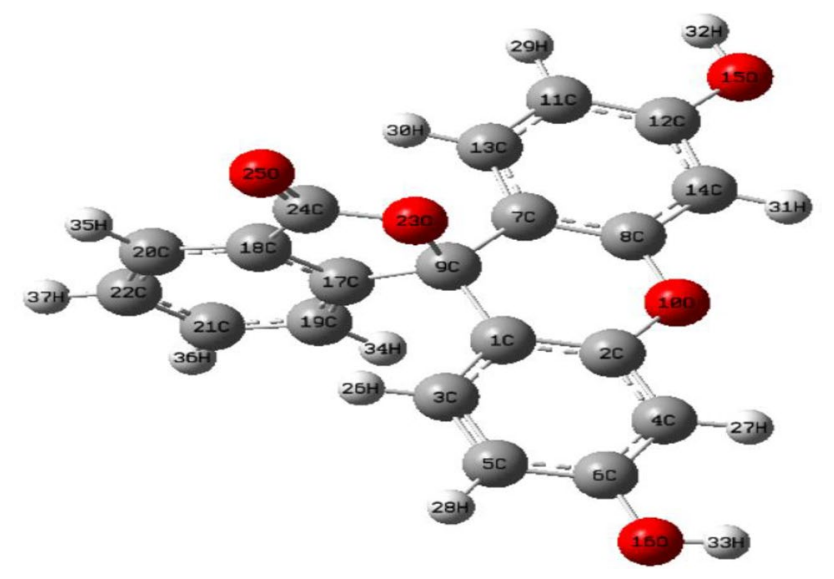

Fig. 3 Fluorescein structure optimized by the DFT method B3LYP/6-311G (d, p)

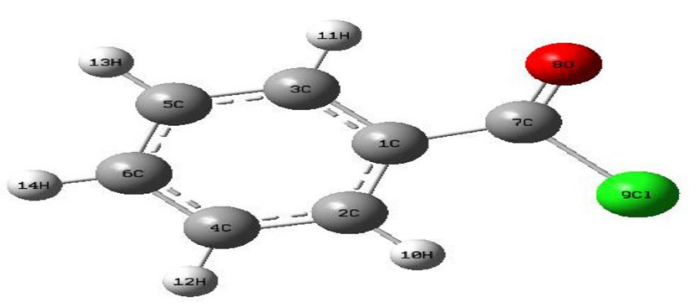

Fig. 4 Structure of benzoyl chloride optimized by the DFT method B3LYP/6-311G (d, p)
Table 6 Thermodynamic quantities characterizing the reaction of fluorescein $\mathrm{R} 1$ condensation and benzoyl chloride R2 calculated by DFT/ B3LYP 6-311G (d, p)
Thermodynamic quantities of the reaction

\begin{tabular}{lr}
\hline$\Delta \mathrm{H}$ (Kcal/mole $)$ & -53.3427 \\
$\Delta \mathrm{S}$ (Kcal/mole.K) & -0.0149 \\
$\Delta \mathrm{G}$ (Kcal/mole $)$ & -57.8049
\end{tabular}

\subsubsection{Theoretical study of the condensation reaction of fluorescein (R1) and benzoyl chloride (R2)}

4.2.3.1 Thermodynamic study We have carefully gathered some thermodynamic quantities properly characterizing the possible reaction of condensation of R1 on R2 in Table 6.

The enthalpy value of the $\Delta \mathbf{H}_{\mathbf{r}}$ reaction is negative, hence the exothermic nature of this reaction.

4.2.3.2 Prediction of Electrophile/Nucleophilic Character of Reagents To highlight the electrophilic/nucleophilic nature of the reagents, we precisely calculated:

- The HOMO/LUMO energy gaps of the favorable reaction, and the HOMO and LUMO molecular orbital energies of each reagent.

- The gap energies $\Delta \mathbf{E}$, the electronic chemical potentials $\boldsymbol{\mu}$, the chemical hardness $\boldsymbol{\eta}$, the global electrophile indices $\boldsymbol{\omega}$, the global nucleophilic indices $\mathbf{N}$, by the following equations $[28,29]$ :

$$
\begin{aligned}
& \Delta E(\mathrm{I})=E_{\mathrm{HOMO}}(\text { fluo })-E_{\mathrm{LUMO}}(\mathrm{BzCl}) \\
& \Delta E(\mathrm{II})=E_{\mathrm{HOMO}}(\mathrm{BzCl})-E_{\mathrm{LUMO}}(\text { fluo }) \\
& \omega=\mu^{2} / 2 * \eta \\
& \mu=\left(E_{\mathrm{HOMO}}+E_{\mathrm{LUMO}}\right) / 2 \\
& \eta=E_{\mathrm{LUMO}}-E_{\mathrm{HOMO}} \\
& N=E_{\mathrm{HOMO}}-E_{\mathrm{HOMO}(\mathrm{TCE})}
\end{aligned}
$$

with $\boldsymbol{E}_{\text {Hомо }}(\mathrm{TCE})=-\mathbf{9 . 3 6 8 6} \mathrm{eV}$ calculated by DFT/B3LYP 6-311G (d, p).

The results from Table 7 and Fig. 5 show that the $\mid E_{\text {HO }}$ (fluo) $-\boldsymbol{E}_{\text {Lumo }}(\mathrm{BzCl}) \mid$ gaps, of the order of $\mathbf{2 . 1 0 6 2 ~ e V}$, are energetically lower than the gaps $\mid \boldsymbol{E}_{\text {Hомо }}(\mathrm{BzCl})-\boldsymbol{E}_{\text {Lumo }}$ (fluo)| which are of the order of $6.1000 \mathrm{eV}$. This shows that benzoyl chloride has an electrophilic character whereas fluorescein behaves like a nucleophile [30].

4.2.3.3 Theoretical analysis of reagents by global properties Table 8 shows that the chemical potential $\mu$ of fluorescein $(\boldsymbol{\mu}=\mathbf{- 2 . 3 4 6 8} \mathbf{e V})$ is on a level of energy higher 
Table $7 \mathrm{HOMO}$ and LUMO energies, and the energy differences between the two possible HOMO/LUMO combinations of the reagents by the DFT/B3LYP method in the base $(6-311 \mathrm{G})(\mathrm{d}, \mathrm{p})$

\begin{tabular}{|c|c|c|c|c|c|}
\hline Compound & $\mathrm{E}(\mathrm{eV})$ & HOMO $(\mathrm{eV})$ & LUMO (eV) & $\Delta \mathrm{E}(\mathrm{I})(\mathrm{eV})$ & $\Delta \mathrm{E}(\mathrm{II}) \mathrm{eV}$ \\
\hline $\mathrm{R} 1$ & $-31,171.2957$ & -6.1304 & -1.4367 & -2.1062 & -6.1000 \\
\hline $\mathrm{R} 2$ & $-21,910.5026$ & -7.3754 & -2.1617 & & \\
\hline
\end{tabular}

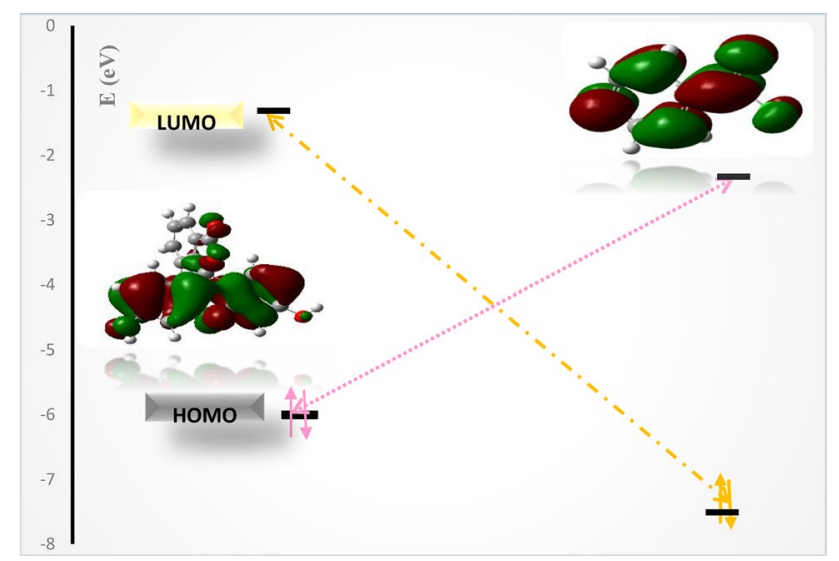

Fig. 5 HOMO and LUMO Energy Diagram of Reagents

than of benzoyl chloride $(\boldsymbol{\mu}=\mathbf{- 2 . 6 0 6 8} \mathbf{e V})$, which naturally implies that electron transfer takes place from fluorescein to benzoyl chloride.

The global nucleophilicity $\mathbf{N}$ of fluorescein $(\mathbf{N}=\mathbf{2 . 9 8 8 1} \mathbf{~ e V})$ is significantly higher than of benzoyl chloride $(\mathbf{N}=\mathbf{1 . 7 4 3 2} \mathbf{e V})$, which means that fluorescein plays the role of a nucleophile whereas $\mathbf{B z} \mathbf{C l}$ is an electrophile. The same conclusion can be correctly deduced from the values of the global electrophilicity $\boldsymbol{\omega}$. The chemical hardness of fluorescein $(\boldsymbol{\eta}=\mathbf{4 . 6 9 3 7} \mathbf{e V})$ is less than of benzoyl chloride $(\boldsymbol{n}=\mathbf{5 . 2 1 3 7} \mathbf{e V})$, which means that fluorescein retains few electrons in its environment, unlike benzoyl chloride which maintains them in its environment, and consequently, the possible transfer of electrons takes place from fluorescein to benzoyl chloride.

In conclusion, HOMO/LUMO Gap calculations, electronic chemical potentials and global electrophilicity and nucleophilicity indices show globally the nucleophilic nature of fluorescein and the electrophilic character of benzoyl chloride.

\subsubsection{Prediction of local reactivity of reagents}

- Application of the Domingo polar model, using Fukui indices $\mathrm{fk}^{+}$and $\mathrm{fk}^{-}$

According to Domingo's polar model [31], the static indices of local electrophilicity $\omega_{\mathbf{k}}$ and local nucleophilicity $\mathbf{N}_{\mathbf{k}}$ are reliable descriptors for the prediction of the most favored electrophilic-nucleophilic interaction for the formation of a chemical bond between two atoms. It occurs between the most electrophilic site (characterized by the highest value of $\boldsymbol{\omega}_{\mathbf{k}}$ ) of the electrophilic molecule and the nucleophilic site (characterized by the highest $\mathbf{N}_{\mathbf{k}}$ value) of the nucleophilic molecule. The local electrophilic values $\boldsymbol{\omega}_{\mathbf{k}}$ for the reactive atoms and the local nucleophilic $\mathbf{N}_{\mathbf{k}}$ of the benzoyl chloride and fluorescein atoms calculated from the natural NPA populations by the DFT/B3LYP 6-311G (d, p) method are correctly reported in Tables 9 and 10.

$\omega_{k}=\omega * f k^{+}(\omega=0.6517 \mathrm{eV})$ and $N_{k}=N f k^{-}(N=2.9881 \mathrm{eV})$.

$f k^{+}=\left[P_{k}(N+1)-P_{k}(N)\right]$ for a nucleophilic attack.

$f k^{-}=\left[P_{k}(N)-P_{k}(N-1)\right]$ for an electrophilic attack.

From where:

$\mathbf{P}_{\mathbf{k}}(\mathbf{N})$ electron population of the atom $\mathrm{k}$ in the neutral molecule.

$\mathbf{P}_{\mathbf{k}}(\mathbf{N}+\mathbf{1})$ electron population of the $\mathrm{K}$ atom in the anionic molecule.

$\mathbf{P}_{\mathbf{k}}(\mathbf{N}-\mathbf{1})$ electron population of the $\mathrm{K}$ atom in the cationic molecule.

The results obtained are not in agreement with those desired in the synthesis, as the values of the Fukui indices are low in the $\mathbf{O}_{15}$ and $\mathbf{O}_{16}$ sites. This indicates that the neutral form of fluorescein does not give a good approach to the reaction, hence the need to work with a base to extract the two protons from the fluorescein diols. pH remains,

Table 8 Electronic chemical potential $\boldsymbol{\mu}$, hardness $\boldsymbol{\eta}$, global electrophilicity $\boldsymbol{\omega}$, global nucleophilicity $\mathbf{N}$, B3LYP DFT/6-311G (d, p)

\begin{tabular}{lllllll}
\hline Compound & $\mathrm{E}(\mathrm{eV})$ & $\mu(\mathrm{eV})$ & $\eta(\mathrm{eV})$ & $\mathrm{S}(\mathrm{I})(\mathrm{eV})$ & $\omega(\mathrm{eV})$ & $\mathrm{N}(\mathrm{eV})$ \\
\hline R1 & $-31,171.2957$ & -2.3468 & 4.6937 & 0.1065 & 0.5867 & 2.9881 \\
R2 & $-21,910.5026$ & -2.6068 & 5.2137 & 0.0959 & 0.6517 & 1.7432 \\
\hline
\end{tabular}


Table 9 Natural populations of reagents calculated by the DFT/ B3LYP 6-311G method $(d, p)$

\begin{tabular}{|c|c|c|c|c|c|}
\hline \multicolumn{6}{|c|}{ Natural populations } \\
\hline \multicolumn{3}{|c|}{ Fluorescein } & \multicolumn{3}{|l|}{$\mathrm{BzCl}$} \\
\hline Atoms & $\mathrm{P}(\mathrm{N})$ & $P(N-1)$ & Atoms & $\mathrm{P}(\mathrm{N})$ & $P(N+1)$ \\
\hline $\mathrm{C}_{1}$ & 6.15300 & 6.05094 & $C_{1}$ & 6.19641 & 6.22304 \\
\hline $\mathrm{C}_{2}$ & 5.65370 & 5.61948 & $C_{2}$ & 6.18291 & 6.27453 \\
\hline$C_{3}$ & 6.18664 & 6.18842 & $C_{3}$ & 6.17434 & 6.26748 \\
\hline $\mathrm{C}_{4}$ & 6.35306 & 6.32610 & $\mathrm{C}_{4}$ & 6.23975 & 6.25777 \\
\hline$C_{5}$ & 6.30583 & 6.17120 & $C_{5}$ & 6.24073 & 6.25664 \\
\hline $\mathrm{C}_{6}$ & 5.65439 & 5.63749 & $\mathrm{C}_{6}$ & 6.19497 & 6.33385 \\
\hline$C_{7}$ & 6.15164 & 6.07941 & $C_{7}$ & 5.42839 & 5.60947 \\
\hline $\mathrm{C}_{8}$ & 5.6562 & 5.63102 & $\mathbf{O}_{8}$ & 8.50923 & 8.66091 \\
\hline $\mathrm{C}_{9}$ & 5.74195 & 5.75232 & & & \\
\hline $\mathrm{O}_{10}$ & 8.48562 & 8.36704 & & & \\
\hline$C_{11}$ & 6.32575 & 6.21142 & & & \\
\hline$C_{12}$ & 5.65537 & 5.64789 & & & \\
\hline$C_{13}$ & 6.18392 & 6.17839 & & & \\
\hline$C_{14}$ & 6.33306 & 6.29615 & & & \\
\hline $\mathrm{O}_{15}$ & 8.69874 & 8.67317 & & & \\
\hline $\mathrm{O}_{16}$ & 8.69839 & 8.66215 & & & \\
\hline$C_{17}$ & 6.01968 & 6.03323 & & & \\
\hline$C_{18}$ & 6.1753 & 6.1694 & & & \\
\hline $\mathrm{C}_{19}$ & 6.22323 & 6.21679 & & & \\
\hline$C_{20}$ & 6.19041 & 6.18343 & & & \\
\hline$C_{21}$ & 6.20644 & 6.19872 & & & \\
\hline $\mathrm{C}_{22}$ & 6.23717 & 6.22533 & & & \\
\hline $\mathrm{O}_{23}$ & 8.54861 & 8.53162 & & & \\
\hline$C_{24}$ & 5.17982 & 5.17612 & & & \\
\hline $\mathrm{O}_{25}$ & 8.61000 & 8.58076 & & & \\
\hline
\end{tabular}

also, a parameter to be conditioned to conduct to this reactive form of fluorescein (Fig. 6).

The satisfactory answer to this ambiguity was discovered by utilizing the MARVINSKETCH software. The distribution of the protonated forms as a function of the $\mathbf{p H}$ shows that the desired shape can take place at a $\mathbf{p H}$ in the vicinity of 14 (Fig. 7).

We proceeded by recalculating the same starting parameters, this time with fluorescein in basic medium.

$\Delta E(\mathrm{I})=E_{\mathrm{HOMO}}($ basic fluorescein $)-E_{\mathrm{LUMO}}($ benzoyl chloride $)$

$\Delta E(\mathrm{II})=E_{\mathrm{HOMO}}($ benzoyl chloride $)-E_{\mathrm{LUMO}}($ fluorescein $)$

The results from Table 11 show again that the $\mid E_{\text {номо }}$ (fluo) $-E_{\mathrm{LUMO}}(\mathrm{BzCl}) \mid$ are energetically weaker than the $\mid \boldsymbol{E}_{\text {номо }}(\mathrm{BzCl})-\boldsymbol{E}_{\text {LUmo }}$ (fluo) $\mid$ gaps, and therefore benzoyl chloride behaves as an electrophile while Fluorescein behaves like a nucleophile.
Table 10 Fukui indices ( $\mathbf{f k}^{+}$and $\mathbf{f k}^{-}$) and local electrophilicity values $\boldsymbol{\omega}_{\mathbf{k}}$ for reactive $\mathbf{B z C l}$ atoms and $\mathbf{N}_{\mathbf{k}}$ local nucleophilicity for reactive fluorescein atoms calculated by NPA natural population analysis

Local indices NPA

\begin{tabular}{|c|c|c|c|c|c|}
\hline \multicolumn{3}{|c|}{ Fluorescein } & \multicolumn{3}{|l|}{$\mathrm{BzCl}$} \\
\hline Atoms & $f-$ & $\mathrm{N}_{\mathrm{k}}$ & Atoms & $f+$ & $\omega k$ \\
\hline $\mathrm{C}_{1}$ & 0.102 & 0.305 & $C_{1}$ & 0.027 & 0.017 \\
\hline$C_{2}$ & 0.034 & 0.102 & $C_{2}$ & 0.092 & 0.060 \\
\hline$C_{3}$ & -0.002 & -0.005 & $C_{3}$ & 0.093 & 0.061 \\
\hline $\mathrm{C}_{4}$ & 0.027 & 0.081 & $C_{4}$ & 0.018 & 0.012 \\
\hline$C_{5}$ & 0.135 & 0.402 & $C_{5}$ & 0.016 & 0.010 \\
\hline $\mathrm{C}_{6}$ & 0.017 & 0.050 & $C_{6}$ & 0.139 & 0.091 \\
\hline$C_{7}$ & 0.072 & 0.216 & $C_{7}$ & 0.181 & 0.118 \\
\hline $\mathrm{C}_{8}$ & 0.025 & 0.075 & $\mathbf{O}_{8}$ & 0.152 & 0.099 \\
\hline $\mathrm{C}_{9}$ & -0.010 & -0.031 & & & \\
\hline $\mathrm{O}_{10}$ & 0.119 & 0.354 & & & \\
\hline$C_{11}$ & 0.114 & 0.342 & & & \\
\hline$C_{12}$ & 0.007 & 0.022 & & & \\
\hline$C_{13}$ & 0.006 & 0.017 & & & \\
\hline $\mathrm{C}_{14}$ & 0.037 & 0.110 & & & \\
\hline $\mathrm{O}_{15}$ & 0.026 & 0.076 & & & \\
\hline $\mathrm{O}_{16}$ & 0.036 & 0.108 & & & \\
\hline$C_{17}$ & -0.014 & -0.040 & & & \\
\hline $\mathrm{C}_{18}$ & 0.006 & 0.018 & & & \\
\hline $\mathrm{C}_{19}$ & 0.006 & 0.019 & & & \\
\hline$C_{20}$ & 0.007 & 0.021 & & & \\
\hline$C_{21}$ & 0.008 & 0.023 & & & \\
\hline$C_{22}$ & 0.012 & 0.035 & & & \\
\hline $\mathrm{O}_{23}$ & 0.017 & 0.051 & & & \\
\hline $\mathrm{C}_{24}$ & 0.004 & 0.011 & & & \\
\hline $\mathrm{O}_{25}$ & 0.029 & 0.087 & & & \\
\hline
\end{tabular}

4.2.3.5 Theoretical analysis of reagents by global properties Table 12 shows that the chemical potential $\boldsymbol{\mu}$ of fluorescein $(\boldsymbol{\mu}=\mathbf{- 1 . 4 9 6 2} \mathbf{e V})$ is on a level of energy higher

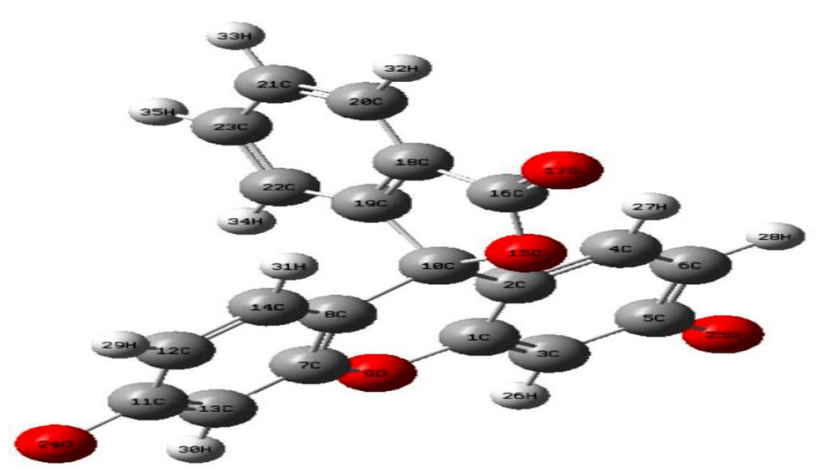

Fig. 6 Structure of fluorescein in a basic medium optimized by the DFT method B3LYP/6-311G (d, p) 
Fig. 7 Distribution of different forms of fluorescein as a function of $\mathrm{pH}$

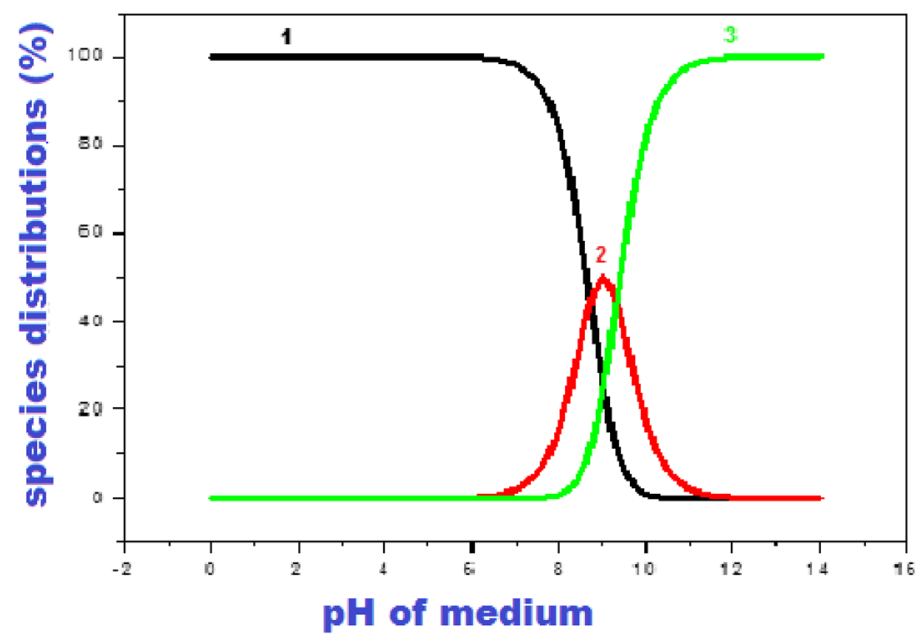

Table 11 HOMO and LUMO energies and the energy differences between the two possible HOMO/LUMO combinations of DFT/B3LYP reagents, 6-311G $(d, p)$

\begin{tabular}{|c|c|c|c|c|c|}
\hline Compound & $E(e V)$ & $\mathrm{HOMO}(\mathrm{eV})$ & LUMO $(\mathrm{eV})$ & $\Delta \mathrm{E}(\mathrm{I})(\mathrm{eV})$ & $\Delta \mathrm{E}(\mathrm{II})(\mathrm{eV})$ \\
\hline Fluorescein (basic form) & $-27,222.1197$ & -4.2678 & -1.2754 & -2.1062 & -6.1000 \\
\hline Benzoyl chloride & $-21,910.5026$ & -7.3754 & -2.1617 & & \\
\hline
\end{tabular}

Table 12 Electronic chemical potential $\boldsymbol{\mu}$, global hardness $\boldsymbol{\eta}$, global electrophilicity $\boldsymbol{\omega}$, global nucleophilicity N, B3LYP DFT/6-311G (d, p)

\begin{tabular}{lllllll}
\hline Compound & $\mathrm{E}(\mathrm{eV})$ & $\mu(\mathrm{eV})$ & $\eta(\mathrm{eV})$ & $\mathrm{S}(\mathrm{I})(\mathrm{eV})$ & $\omega(\mathrm{eV})$ & $\mathrm{N}(\mathrm{eV})$ \\
\hline Neutral fluorescein & $-31,171.2957$ & -2.3468 & 4.6937 & 0.1065 & 0.5867 & 2.9881 \\
Basic fluorescein & $-31,144.6797$ & -1.4962 & 2.9924 & 0.1671 & 0.3741 & 4.8507 \\
Benzoyl chloride & $-21,910.5026$ & -2.6068 & 5.2137 & 0.0959 & 0.6517 & 1.7432 \\
\hline
\end{tabular}

than that of benzoyl chloride $(\boldsymbol{\mu}=\mathbf{- 2 . 6 0 6 8} \mathbf{e V})$, which implies that electron transfer takes place from fluorescein to benzoyl chloride. We note this time that the value of the nucleophile index of basic fluorescein is greater than that obtained for the neutral fluorescein, which watches the importance of the practical use of the base in the desired reaction ensuring its efficient approach. On the other hand, the results obtained show that, in basic medium, the nucleophilic index $(\mathbf{N}=\mathbf{4 . 8 5 0 7} \mathbf{~ e V})$ is higher than that of benzoyl chloride $(\mathbf{N}=\mathbf{1 . 7 4 3 2} \mathbf{e V})$, which means that fluorescein is a nucleophile while benzoyl chloride is an electrophile. The same conclusion can be deduced from the values of electrophilic indices (Tables 13, 14).

\subsubsection{Prediction of local reactivity of reagents}

- Application of the Domingo polar model, using Fukui indices $\mathrm{fk}+$ and $\mathrm{fk}$ -

From natural populations, we calculated local Fukui indices of the reagents used to synthesize the desired product.

This time, the local $\mathbf{N}_{\mathbf{k}}$ nucleophilic indices for the fluorescein reactive atoms in the basic medium and the local electrophilic indices $\boldsymbol{\omega}_{\mathbf{k}}$ for the benzoyl chloride atoms show that the most favored interaction naturally takes place between the most electrophilic site (identified by the highest value of $\boldsymbol{\omega}_{\mathbf{k}}$ ) of the electrophilic molecule and the nucleophilic site (distinguished by the highest $\mathbf{N}_{\mathbf{k}}$ value) of the nucleophilic molecule [31]. Consequently, the polar model of Domingo correctly predicts the possible formation of the $\mathbf{O}_{24}-\mathbf{C}_{\mathbf{7}}$ and $\mathbf{O}_{25}-\mathbf{C}_{\mathbf{7}}$ bonds, experimentally desired. 
Table 13 Natural populations of fluorescein in basic medium and $\mathrm{BzCl}$ calculated by the method DFT/B3LYP 6-311G (d, p)

\begin{tabular}{|c|c|c|c|c|c|}
\hline \multicolumn{6}{|c|}{ Natural populations } \\
\hline \multicolumn{3}{|c|}{ Basic fluorescein } & \multicolumn{3}{|c|}{ Benzoyl chloride } \\
\hline Atoms & $\mathrm{P}(\mathrm{N})$ & $P(N-1)$ & Atoms & $\mathrm{P}(\mathrm{N})$ & $P(N+1)$ \\
\hline $\mathrm{C}_{1}$ & 5.64353 & 5.65116 & $C_{1}$ & 6.19641 & 6.22304 \\
\hline $\mathrm{C}_{2}$ & 6.17145 & 6.06191 & $\mathrm{C}_{2}$ & 6.18291 & 6.27453 \\
\hline$C_{3}$ & 6.40879 & 6.32883 & $C_{3}$ & 6.17434 & 6.26748 \\
\hline $\mathrm{C}_{4}$ & 6.20284 & 6.20556 & $\mathrm{C}_{4}$ & 6.23975 & 6.25777 \\
\hline $\mathrm{C}_{5}$ & 5.58542 & 5.57729 & $C_{5}$ & 6.24073 & 6.25664 \\
\hline $\mathrm{C}_{6}$ & 6.33306 & 6.24999 & $C_{6}$ & 6.19497 & 6.33385 \\
\hline$C_{7}$ & 5.64352 & 5.65115 & $C_{7}$ & 5.42839 & 5.60947 \\
\hline $\mathrm{C}_{8}$ & 6.17143 & 6.06193 & $\mathbf{O}_{8}$ & 8.50923 & 8.66091 \\
\hline $\mathrm{O}_{9}$ & 8.4831 & 8.46779 & & & \\
\hline$C_{10}$ & 5.88407 & 5.89783 & & & \\
\hline$C_{11}$ & 5.58541 & 5.57729 & & & \\
\hline$C_{12}$ & 6.33305 & 6.24999 & & & \\
\hline$C_{13}$ & 6.40879 & 6.32883 & & & \\
\hline $\mathrm{C}_{14}$ & 6.20282 & 6.20554 & & & \\
\hline $\mathrm{O}_{15}$ & 8.76686 & 8.75892 & & & \\
\hline$C_{16}$ & 5.23148 & 5.22608 & & & \\
\hline $\mathrm{O}_{17}$ & 8.79047 & 8.78088 & & & \\
\hline $\mathrm{C}_{18}$ & 6.12886 & 6.12296 & & & \\
\hline $\mathrm{C}_{19}$ & 6.05703 & 6.07787 & & & \\
\hline$C_{20}$ & 6.22225 & 6.21693 & & & \\
\hline$C_{21}$ & 6.25137 & 6.24099 & & & \\
\hline$C_{22}$ & 6.23176 & 6.22804 & & & \\
\hline$C_{23}$ & 6.24311 & 6.23744 & & & \\
\hline $\mathrm{O}_{24}$ & 8.72036 & 8.5849 & & & \\
\hline $\mathrm{O}_{25}$ & 8.72036 & 8.58489 & & & \\
\hline
\end{tabular}

- Application of the Gazquez-Mendez rule using condensed local softness (Sk + and Sk-)

According to the Gazquez-Mendez rule [32], "Two chemical species interact through atoms with equal or similar softness." The values of local softness $\mathbf{S k}^{-}$for the reactive atoms of fluorescein and local softness $\mathbf{S k}^{+}$for the reactive atoms of benzoyl chloride, calculated with the NPA population analysis, are given in Table 15.

$$
\begin{aligned}
& S k^{+}=S f k^{+}\left(S=1 / 2 * \eta=0.0959 \mathrm{eV}^{-1}\right) \text { and } \\
& S k^{-}=S f k^{-}\left(S=0.1671 \mathrm{eV}^{-1}\right)
\end{aligned}
$$

[33].

Table 15 also shows that the most favored interactions naturally take place between the atom $\mathbf{C}_{\mathbf{7}}$ of benzoyl chloride and the $\mathbf{O}_{\mathbf{2 4}}$ and $\mathbf{O}_{25}$ fluorescein (neighboring local softness and Ring local softness), which is in good agreement with the experimentally desired results.
Table 14 Fukui indices ( $\mathbf{f k}^{+}$and $\mathbf{f k}^{-}$) and local electrophilicity values $\boldsymbol{\omega}_{\mathbf{k}}$ for reactive $\mathrm{BzCl}$ atoms and local $\mathbf{N}_{\mathbf{k}}$ nucleophilicity for reac-

\begin{tabular}{|c|c|c|c|c|c|}
\hline \multicolumn{6}{|c|}{ Local indices NPA } \\
\hline \multicolumn{3}{|c|}{ Basic fluorescein } & \multicolumn{3}{|c|}{ Benzoyl chloride } \\
\hline Atoms & $f^{-}$ & $\mathrm{N}_{\mathrm{k}}$ & Atoms & $\mathrm{f}^{+}$ & $\omega_{k}$ \\
\hline $\mathrm{C}_{1}$ & -0.008 & -0.037 & $C_{1}$ & 0.027 & 0.017 \\
\hline $\mathrm{C}_{2}$ & 0.110 & 0.531 & $C_{2}$ & 0.092 & 0.060 \\
\hline$C_{3}$ & 0.080 & 0.388 & $C_{3}$ & 0.093 & 0.061 \\
\hline $\mathrm{C}_{4}$ & -0.003 & -0.013 & $C_{4}$ & 0.018 & 0.012 \\
\hline$C_{5}$ & 0.008 & 0.039 & $C_{5}$ & 0.016 & 0.010 \\
\hline $\mathrm{C}_{6}$ & 0.083 & 0.403 & $\mathrm{C}_{6}$ & 0.139 & 0.091 \\
\hline$C_{7}$ & -0.008 & 0.037 & $C_{7}$ & 0.181 & 0.118 \\
\hline $\mathrm{C}_{8}$ & 0.110 & 0.531 & $\mathbf{O}_{8}$ & 0.152 & 0.099 \\
\hline $\mathrm{O}_{9}$ & 0.015 & 0.074 & & & \\
\hline$C_{10}$ & -0.014 & 0.067 & & & \\
\hline $\mathrm{C}_{11}$ & 0.008 & 0.039 & & & \\
\hline$C_{12}$ & 0.083 & 0.403 & & & \\
\hline$C_{13}$ & 0.080 & 0.388 & & & \\
\hline $\mathrm{C}_{14}$ & -0.003 & 0.013 & & & \\
\hline $\mathrm{O}_{15}$ & 0.008 & 0.039 & & & \\
\hline$C_{16}$ & 0.005 & 0.026 & & & \\
\hline $\mathrm{O}_{17}$ & 0.010 & 0.047 & & & \\
\hline $\mathrm{C}_{18}$ & 0.006 & 0.029 & & & \\
\hline $\mathrm{C}_{19}$ & -0.021 & -0.101 & & & \\
\hline$C_{20}$ & 0.005 & 0.026 & & & \\
\hline$C_{21}$ & 0.010 & 0.050 & & & \\
\hline$C_{22}$ & 0.004 & 0.018 & & & \\
\hline$C_{23}$ & 0.006 & 0.028 & & & \\
\hline $\mathrm{O}_{24}$ & 0.135 & 0.657 & & & \\
\hline $\mathrm{O}_{25}$ & 0.135 & 0.657 & & & \\
\hline
\end{tabular}
tive basic fluorescein atoms calculated by NPA population analysis

\section{Conclusion}

The nucleophilic substitution of fluorescein with benzoyl chloride occurred under very mild conditions and led to the 3-oxo-3H-spiro[isobenzofuran-1,9'-xanthene]-3',6'-diyl dibenzoate in high yield. The structure of the synthesized product was analyzed by MS, Infrared, ${ }^{13} \mathrm{C}$ NMR and ${ }^{1} \mathrm{H}$ NMR. The mild reaction conditions, use of an environmentally benign method, rapid conversion, very satisfactory yields, and wide applicability represent the notable advantages of the present method. This reaction has been studied also using MARVINSKETCH to find a range of $\mathrm{pH}$ in the major form of fluorescein in basic medium and Gaussian 09 program within the DFT calculations at the B3LYP/6-311 $(d, p)$ computational level. The analysis of the electrophilic and nucleophilic Parr functions of reagents and an exploration of the values of the energies $E$ and $\Delta E$ of the reaction indicates it takes place through a two-step mechanism. The exothermic nature of the reaction makes 
Table 15 Fukui indexes ( $\mathbf{f k}^{+}$and $\mathbf{f k} \mathbf{k}^{-}$) and $\mathbf{S} \mathbf{k}^{-}$local softness values for fluorescein reactive atoms and $\mathbf{S \mathbf { k } ^ { + }}$ local softness for the reactive benzoyl chloride atoms, calculated by NPA populations

\begin{tabular}{|c|c|c|c|c|c|}
\hline \multicolumn{6}{|c|}{ Local indices NPA } \\
\hline \multicolumn{3}{|c|}{ Basic fluorescein } & \multicolumn{3}{|c|}{ Benzoyl chloride } \\
\hline Atoms & $f^{-}$ & $\mathrm{S}^{-}$ & Atoms & $f^{+}$ & $\mathrm{S}^{+}$ \\
\hline $\mathrm{C}_{1}$ & -0.008 & -0.001 & $c_{1}$ & 0.027 & 0.003 \\
\hline $\mathrm{C}_{2}$ & 0.110 & 0.018 & $C_{2}$ & 0.092 & 0.009 \\
\hline$C_{3}$ & 0.080 & 0.013 & $C_{3}$ & 0.093 & 0.009 \\
\hline $\mathrm{C}_{4}$ & -0.003 & 0.000 & $\mathrm{C}_{4}$ & 0.018 & 0.002 \\
\hline $\mathrm{C}_{5}$ & 0.008 & 0.001 & $C_{5}$ & 0.016 & 0.002 \\
\hline $\mathrm{C}_{6}$ & 0.083 & 0.014 & $C_{6}$ & 0.139 & 0.013 \\
\hline$C_{7}$ & -0.008 & -0.001 & $C_{7}$ & 0.181 & 0.017 \\
\hline $\mathrm{C}_{8}$ & 0.110 & 0.018 & $\mathbf{O}_{8}$ & 0.152 & 0.015 \\
\hline $\mathrm{O}_{9}$ & 0.015 & 0.003 & & & \\
\hline$C_{10}$ & -0.014 & -0.002 & & & \\
\hline$C_{11}$ & 0.008 & 0.001 & & & \\
\hline$C_{12}$ & 0.083 & 0.014 & & & \\
\hline$C_{13}$ & 0.080 & 0.013 & & & \\
\hline $\mathrm{C}_{14}$ & -0.003 & 0.000 & & & \\
\hline $\mathrm{O}_{15}$ & 0.008 & 0.001 & & & \\
\hline$C_{16}$ & 0.005 & 0.001 & & & \\
\hline $\mathrm{O}_{17}$ & 0.010 & 0.002 & & & \\
\hline $\mathrm{C}_{18}$ & 0.006 & 0.001 & & & \\
\hline $\mathrm{C}_{19}$ & -0.021 & -0.003 & & & \\
\hline$C_{20}$ & 0.005 & 0.001 & & & \\
\hline$C_{21}$ & 0.010 & 0.002 & & & \\
\hline$C_{22}$ & 0.004 & 0.001 & & & \\
\hline$C_{23}$ & 0.006 & 0.001 & & & \\
\hline $\mathrm{O}_{24}$ & 0.135 & 0.023 & & & \\
\hline $\mathrm{O}_{25}$ & 0.135 & 0.023 & & & \\
\hline
\end{tabular}

the formation of the new product $\mathbf{3}$ irreversible, favored thermodynamically and kinetically in good agreement with the experimental result.

Acknowledgements We thank the CNRST for the financial support of this work (PROTARS D13/03, Morocco).

\section{Compliance with ethical standards}

Conflict of interest The authors declare that they have no Conflict of interest.

\section{References}

1. Wioleta C, Joanna S, Anna K-R (2020) Antifungal styryloquinolines as Candida albicans efflux pump inhibitors: styryloquinolines are $A B C$ transporter inhibitors. Molecules 25:345. https:// doi.org/10.3390/molecules25020345

2. Ameen AH, Sami A-H, Magdi AZ (2020) Synthesis of novel benzodifuranyl; 1,3,5-triazines; 1,3,5-oxadiazepines; and thiazolopyrimidines derived from visnaginone and khellinone as anti-inflammatory and analgesic agents. Molecules 25:220. https://doi.org/10.3390/molecules 25010220

3. Mousa LA-S, Reem M, Amjad M, Omar FK, Majed M, Masadeh KH (2019) Synthesis, characterization, antimicrobial activity, and genotoxicity assessment of two heterocyclic compounds containing 1,2,3-selena- or 1,2,3-thiadiazole rings. Molecules 24(22):4082. https://doi.org/10.3390/molecules 24224082

4. Sayran SS, Siham AS, Israa AM (2019) Biological activity Study for some heterocyclic compounds and their impact on the grampositive and negative bacteria. Energy Procedia 157:296-306. https://doi.org/10.1016/j.egypro.2018.11.194

5. Dua R, Shrivastava S, Sonwane SK, Srivastava SK (2011) Pharmacological significance of synthetic heterocycles scaffold. Adv Biol Res 5(3):120-144

6. Gomtsyan A (2012) Heterocycles in drugs and drug discovery. Chem Heterocycl Compd 48:7-10. https://doi.org/10.1007/ s10593-012-0960-z

7. Paphitou NI (2013) Antimicrobial resistance: action to combat the rising microbial challenges. Int J Antimicrob Agents 42:8-25. https://doi.org/10.1016/j.ijantimicag.2013.04.007

8. Gould IM, David MZ, Esposito S, Garau J, Lina G, Mazzei T, Peters G (2012) New insights into meticillin-resistant Staphylococcus aureus (MRSA) pathogenesis, treatment, and resistance. Int J Antimicrob Agents 39(2):96-104. https://doi.org/10.1016/j.ijant imicag.2011.09.028

9. Singh M, Raghav N (2011) Biological activities of hydrazones. Int J Pharm Sci 3(4):26-32

10. Theuretzbacher U (2013) Global antibacterial resistance. The never-ending story. J Global Antimicrob Resist 1(2):63-69. https ://doi.org/10.1016/j.jgar.2013.03.010

11. Nareshvarma PS, Prasanthi S, Supriya G (2016) Synthesis and in vitro study of some fused 1,2,4-triazole derivatives as antimycobacterial agents. J Saudi Chem Soc 20:411-418. https:// doi.org/10.1016/j.jscs.2012.11.011

12. Sultivan TJ, Truglio JJ, Boyne ME, Novichenok P, Zhang X, Stratton CF, Li HJ, Kaur T, Amin A, Johnson F, Stayden RA, Kisker C, Tonge PJ (2007) High-affinity InhA inhibitors with activity against drug-resistant strains of Mycobacterium tuberculosis. ACS Chem Biol 1:43-53. https://doi.org/10.1021/cb0500042

13. Gilbert AM, Failli A, Shumsky J, Yang Y, Severin A, Singh G, Hu W, Keeney D, Petersen PJ, Katz AH (2006) Pyrazolidine-3,5-diones and 5-hydroxy-1 H-pyrazol-3(2H)-ones, inhibitors of UDP-N-acetylenolpyruvyl glucosamine reductase. J Med Chem 49:60276036. https://doi.org/10.1021/jm060499t

14. Prakash O, Kumar R, Parkash V (2008) Synthesis and antifungal activity of some new 3-hydroxy-2-(1-phenyl-3-aryl-4-pyrazolyl) chromones. Eur J Med Chem 43:435-440. https://doi. org/10.1016/j.ejmech.2007.04.004

15. Isloor AM, Kalluraya B, Shetty P (2009) Regioselective reaction: synthesis, characterization and pharmacological studies of some new Mannich bases derived from 1,2,4-triazoles. Eur J Med Chem 44:3784-3787. https://doi.org/10.1016/j.ejmec h.2009.04.038

16. Magedov IV, Manpadi M, Slambrouck SV, Steelant FA, Rozhkova E, Przheval'skii NM, Rogelj S, Kornienko A (2007) Discovery and investigation of antiproliferative and apoptosis-inducing properties of new heterocyclic podophyllotoxin analogues accessible by a one-step multicomponent synthesis. J Med Chem 50:5183-5192. https://doi.org/10.1021/jm070528f

17. Szabo G, Fischer J, Kis-Varga A, Gyires K (2007) New celecoxib derivatives as anti-inflammatory agents. J Med Chem 51:142147. https://doi.org/10.1021/jm070821f

18. Benaamane N, Nedjar-Kolli B, Bentarzi Y, Hammal L, Geronikaki A, Eleftheriou P, Langunin A (2008) Synthesis and in silico 
biological activity evaluation of new N-substituted pyrazolooxazin-2-one systems. Bioorg Med Chem 16:3059-3066

19. Prasad YR, Lakshmana RA, Prasoona L, Murali K, Ravi KP (2005) Synthesis and antidepressant activity of some 1,3,5-triphenyl-2-pyrazolines and 3-(2"-hydroxy naphthalen-1"-yl)-1,5diphenyl-2-pyrazolines. Bioorg Med Chem Lett 15:5030-5034. https://doi.org/10.1016/j.bmcl.2005.08.040

20. Ozdemir Z, Kandilici HB, Gumusel B, Calis U, Bilgin AA (2007) Synthesis and studies on an antidepressant and anticonvulsant activities of some 3-(2-furyl)-pyrazoline derivatives. Eur J Med Chem 42:373-379. https://doi.org/10.1016/j.ejmec h.2006.09.006

21. Sener A, Sener MK, Bildmci I, Kasimogullari R, Akcamur Y (2002) Studies on the reactions of cyclic oxalyl compounds with hydrazines or hydrazones II: synthesis and reactions of 4-benzoyl-1-(3nitrophenyl)-5-phenyl-1 H-pyrazole-3-carboxylic acid. J Heterocycl Chem 39:869-875. https://doi.org/10.1002/jhet.55703 90503

22. Monici M (2005) Cell and tissue autofluorescence research and diagnostic applications. Biotechnol Ann Rev 11:227-256. https ://doi.org/10.1016/S1387-2656(05)11007-2

23. Smalley MK, Silvermann SK (2006) Fluorescence of covalently attached pyrene as a general RNA folding probe Nucl. Acids Res 34:152-166. https://doi.org/10.1093/nar/gkj420

24. Loudet A, Burgess K (2007) BODIPY dyes and their derivatives: synthesis and spectroscopic properties. Chem Rev 107:48914932. https://doi.org/10.1021/cr078381n

25. Eshghi H, Mirzaie N, Asoodeh A (2011) Synthesis of fluorescein aromatic esters in the presence of $\mathrm{P}_{2} \mathrm{O}_{5} / \mathrm{SiO}_{2}$ as a catalyst and their hydrolysis studies in the presence of a lipase. Dye Pigment 89:120-126. https://doi.org/10.1016/j.dyepig.2010.09.013
26. Sousa ME, Pinto MMM (2005) Synthesis of xanthones: an overview. Curr Med Chem 12:2447-2479. https://doi. org/10.2174/092986705774370736

27. Meijere A (2005) Adolf von baeyer: winner of the nobel prize for chemistry 1905. Angew Chem Int Ed 44:7836-7840. https://doi. org/10.1002/anie.200503351

28. Bayer A (1871) Ber. Deutsch Chem Ges 4:555-558. https://doi. org/10.1002/cber.18710040209

29. Castro EVR, Jorge FE (1998) Accurate a universal Gaussian basis set for all atoms of the periodic table. J Chem Phys 108:52255229. https://doi.org/10.1063/1.475959

30. Reed AE, Weinhold F (1983) Natural atomic orbitals and natural population analysis. J Chem Phys 78:4066-4073. https://doi. org/10.1063/1.445134

31. Parr RG, Pearson RG (1983) Absolute hardness: companion parameter to absolute electronegativity. J Am Chem Soc 105:7512-7516. https://doi.org/10.1021/ja00364a005

32. Domingo LR, Pérez $P$ (2011) The nucleophilicity $N$ index in organic chemistry. Org Biomol Chem 9:7168-7175. https://doi. org/10.1039/C1OB05856H

33. Pérez $P$, Domingo LR, Duque-Noreňa $M$, Chamorro EA (2009) A condensed-to-atom nucleophilicity index. An application to the director's effects on the electrophilic aromatic substitutions. J Mol Struct (Theochem) 895:86-91. https://doi.org/10.1016/j. theochem.2008.10.014

Publisher's Note Springer Nature remains neutral with regard to jurisdictional claims in published maps and institutional affiliations. 